\title{
GUATTARI: MÁQUINAS E SUJEITOS POLÍTICOS
}

\author{
Larissa Drigo Agostinho ${ }^{1}$
}

\begin{abstract}
Resumo: A partir de uma apresentação do contexto político e social no interior do qual a obra de Guattari se insere, buscamos definir o debate político francês da década de 60, no campo do marxismo, sobretudo do materialismo histórico em torno da questáo do sujeito da história. O objetivo deste artigo é explicitar as razóes que levam Guattari a romper com o estruturalismo, representado na psicanálise por Lacan e no marxismo por Althusser. A relevância deste texto está na apresentação do conceito de máquina, que se define em oposição ao conceito de estrutura e que, unindo história e inconsciente, visa a traçar o espaço de emergência de um sujeito da história, de um sujeito político.
\end{abstract}

Palavras-Chave: Materialismo histórico. Estruturalismo. Psicanálise e política. História.

\section{INTRODUÇÃo}

Acontece, raramente, de um psicanalista e um militante se encontrarem na mesma pessoa, e ao invés de permanecerem fechados, de encontrar justificativas para permanecerem fechados em si mesmos, eles não cessam de se misturar, de interferir, de comunicar, de tomar-se um pelo outro. É um acontecimento muito raro desde Reich. Pierre-Félix Guattari náo se deixa ocupar com o problema da unidade do Eu. O eu faz parte dessas coisas que é preferível dissolver, sob o assalto conjugado de forças políticas e analíticas. A palavra de Guattari "nós somos todos grupelhos", marca bem a busca por uma nova subjetividade, subjetividade de grupo que não se deixa enclausurar em um todo pronto para reconstruir um eu, ou pior ainda um super-eu, mas se estende por diversos grupos ao mesmo tempo, divisíveis, multiplicáveis, comunicantes e sempre revogáveis. O critério de um bom grupo é que ele não sonha ser único, imortal e significante, como um sindicato de defesa ou segurança, como um ministério de antigos combatentes, mas se liga a um fora que o confronta com possibilidades de non-sens, de morte e de explosão, "dada a sua abertura para outros grupos”. O indivíduo, por sua vez, é um tal grupo. (DELEUZE. In: GUATTARI, 1974, p. I).

${ }_{1}^{1}$ Pós-doutoranda do Programa de Pós-Graduação em Filosofia da Universidade de São Paulo (USP), Sáo Paulo, SP - Brasil (com estágio na Universidade de Paris I). (D) https://orcid.org/0000-00033409-487X E-mail: larissa_drigo@yahoo.com.br. Esta pesquisa é financiada pela FAPESP.

http://dx.doi.org/10.1590/0101-3173.2020.v43n1.07.p103

This is an open-access article distributed under the terms of the Creative Commons Attribution License. 
É com essas palavras que Deleuze descreve o psicanalista e militante com quem escreveu durante décadas. Guattari encarnaria, segundo Deleuze, da maneira mais natural possível, os dois aspectos de um anti-eu: pedra catatônica, corpo cego e enrijecido penetrado de morte assim que ele tira os óculos; mas também aquele que brilha de mil fogos, formigando de vidas múltiplas assim que ele olha, age, ri, pensa, ataca. "Ele se chama Pierre e Félix: potências esquizofrênicas."

A militância de Guattari começou com a Liberação, em 1945. Com 15 anos, ele começa a militar no Partido Comunista, em 48, conhece os militantes trotskistas e passa a fazer parte do Partido comunista internacional; parte para a Iugoslávia de Tito, em 49, em 51, começa a cursar filosofia na Sorbonne, onde também participa ativamente na organização política. Em 53, com alguns professores da Universidade, viaja para a China. Em 55, Guattari se instala definitivamente na clínica de La Borde, integra o GTPSI (Grupo de Trabalho em Psicoterapia e Socioterapia Institucional), organizado por Jean Oury, e, em 1965, cria a FGERI (Federaçáo de Grupos de Estudo e Pesquisa Institucionais), o qual integra, sob o princípio da transversalidade, psiquiatras, psicanalistas, enfermeiros, psicólogos e antropólogos. Surge também, nesse período, a Oposição de Esquerda, braço político da FGERI.

Ao abordar as questóes de orientação que se colocavam para ele, a partir da militância, que visavam em um primeiro momento a clarificar uma situação de afrontamento de grupos distintos e, em seguida, a pensar orientaçôes e estratégias, Guattari explica que, desde que começou trabalhar em La Borde, buscava conciliar a sua militância na extrema esquerda e o fato de ser o primeiro não médico a frequentar o seminário de Lacan. Oscilando entre esses três polos, a prática clínica em La Borde, os seminários de Lacan e o militantismo na extrema esquerda, ele afirmaria, anos depois, em 1980, que estava tentando reconciliar o inconciliável. Ele procura ir além da psicoterapia institucional e propor uma análise institucional. Almejava "recusar uma definição demasiado restrita da psicoterapia institucional"; tratava-se, podemos acrescentar, de expandir o espaço da clínica, de utilizar a psicanálise para compreender relaçóes institucionais, analisá-las e transformá-las. O que Guattari desejava era estudar e colocar em prática relações com práticas similares à da psicoterapia institucional, em outros domínios, como a pedagogia, o urbanismo, o militantismo. Principalmente, dentro do movimento estudantil com o qual ele estava ligado, a l'UNEF e a Mutual Nacional dos Estudantes da França. 
Além disso, eu pensava que nós não podíamos avançar nessa nova "disciplina" a não ser na medida em que ela se instituiria em conexão com questôes políticas mais largas como: aquelas, por exemplo, da oposição comunista, da renovação das formas de luta revolucionária, etc. Essa tentativa durará até maio de 68. Uma "grande ilusão" que não renego. Em certa medida, foi um sucesso incontestável. (GUATTARI, 1974, p. 110).

Guattari descreve os encontros organizados pela F.G.E.R.I., onde se cruzavam pessoas tão diferentes quanto Françoise Dolto, Fernand Deligny, Tosquelles, Jean e Fernand Oury, Roland Dubillard, Maud Mannoni, Laing, Cooper, Tourriba, Gentis e, mesmo, às vezes, Jacques Lacan, além de inúmeros estudantes militantes que foram muito ativos em 68 , como locais de uma "fermentação bastante impressionante".

É nesse contexto que foram desenvolvidos os conceitos de transversalidade, transferência institucional, analisador etc., que estấo reunidos em Psicanálise e transversalidade, publicado em 1972, mas com textos que foram escritos ainda nos anos 60 , o que pode nos ajudar a traçar um panorama do contexto no qual se deu maio de 68 e definir o lugar de Guattari no interior dos debates políticos de seu tempo. Muitos dos seus conceitos fundamentais foram criados a partir de sua experiência clínica e militante, e, no plano teórico, com base em divergências sobretudo em relação ao lacano-althussserianismo. E é justamente esse debate que buscaremos reconstituir aqui.

São dois os textos fundamentais para compreendermos a natureza do debate entre Guattari, de um lado, e o estruturalismo lacano-althusseriano, de outro, "Causalidade, subjetividade e história" e "Máquina e estrutura". As críticas de Guattari a Lacan e Althusser se desenvolvem em função de dois temas centrais - a relação entre a história e a determinação significante e o problema da alienação ou da integração da classe operária ao capitalismo. Nos dois casos, a questão é a mesma: pensar o sujeito da história. Entre esses dois temas, Guattari elabora um conceito que ele chamou de cisão leninista. Esse conceito visa a pensar qual a ação fundamental de Lênin que tornou possível o advento da Revolução Russa. Assim, Guattari introduz um elemento novo para demonstrar a impossibilidade de uma concepção estruturalista do materialismo histórico, a noção de ruptura, ou seja, de revolução.

Em seguida, ele se volta para as lutas políticas, buscando traçar um diagnóstico que pretende expor a natureza da alienação da classe operária ou dos obstáculos com os quais a prática revolucionária deve se confrontar. Não basta um 
novo conceito de política, um novo olhar em relação ao materialismo histórico, uma conceitualização à altura da história, a saber, que seja capaz de compreender as rupturas que a transformam; é preciso também formular conceitos capazes de produzir uma nova análise dos processos de alienação e submissão. Daí a importância da psicanálise. Em Guattari, a crítica da alienação não se centra no indivíduo, mas em grupos, por isso, ela se constitui como crítica e análise das organizaçôes e instituiçôes. É com essa análise crítica que se torna possível pensar em que circunstâncias um sujeito histórico pode fazer irrupçáo e de colocar a imaginação a serviço da política, para construir novas formas de organização.

\section{A ruptura Leninista, a história SOB o Signo da ReVOluÇão}

O materialismo histórico continua sendo, segundo Guattari, o único método válido para a análise histórica, no entanto, é preciso saber escapar do stalinismo que reina na França, na década de 60, o qual o autor atribui ao Partido Comunista Francês. Para isso, é preciso salientar que há um dimensão da política que escapa ao determinismo dialético e que funciona como contraponto dessa determinação.

O PCF era totalmente tributário da política estrangeira da URSS (condenando, por exemplo, a Iugoslávia de Tito, incapaz de criticar a guerra do Vietnã etc.), prisioneiro do gaullismo (guinada ética que associa socialismo e humanismo, acenando assim aos católicos), com uma política determinada pelo jogo das relaçóes econômicas e sociais do capitalismo monopolista de Estado e fixado na conquista eleitoral do poder como único horizonte de luta social. No entanto, o PCF e seus problemas não deveriam "ser capazes de mascarar o fato de que continua a existir na França uma via revolucionária que depende, em parte, da evoluçáo da crise interna que o partido atravessa." (GUATTARI, 1974, p. 183).

A questão aqui é justamente a análise histórica e seus esquecimentos ou o conceito mesmo de história e a causalidade que a move. Guattari ressalta, desde o início desse capítulo, a necessidade e a importância do conceito de corte ou ruptura na compreensão da história.

Ele toma o exemplo do castrismo para enfatizar que, na atual condição, existem, sem dúvida, possibilidades de ruptura na causalidade histórica. $\mathrm{O}$ foco, em seguida, será analisar a intervenção dos bolcheviques em fevereiro e outubro de 1917, a qual rompe com o curso "normal" da história, a saber, 
uma união de centro-esquerda para esperar que os partidos tradicionais retomassem o poder. Com o fim do czarismo, os bolcheviques compreenderam a debandada militar, social, econômica e política como uma vitória das massas. Para Lênin, a imbecilidade da burguesia russa tornava possível que a revolução social se tornasse um objetivo imediato.

Lênin se viu diante de uma situação totalmente imprevisível. Ele mesmo tinha combatido duramente todos aqueles que previam que um tal processo seria inevitável. Restava convencer seu partido. É o que ele procurou fazer com as "teses de abril", onde propunha a "mobilização imediata do partido e das massas para tomar o poder.” Nessa decisão, Guattari (1974, p. 184) vê uma marca histórica que ainda continua viva em nossos dias, ou seja, o desejo pelo poder e sua conquista, que leva à subsequente institucionalização do partido, tragédia maior da revolução.

As teses de abril foram impostas ao seu próprio partido, não sem força. $\mathrm{O}$ corte não ocorreu sem trazer sérias consequências. Muito se opuseram a Lênin, militantes de primeira linha, como Zinoviev e Kamenev, como quem antevia o que o stalinismo traria. Mas Lênin, assim como Trotsky, pela primeira vez em décadas, concordaram que era preciso aproveitar essa brecha, apesar da fraqueza do proletariado russo e sem temer os efeitos bumerangue. "A hora da primeira revolução socialista deveria soar." Muitos argumentaram que nunca a causalidade histórica perdera seus direitos, nesse caso, e que esse corte, o que Guattari chama de ruptura leninista, não passa de um engodo.

Fato é que essa experiência, essa ruptura, esse corte, essa intervenção ou decisão marca para Guattari nosso destino histórico, não apenas pelo que nos deixou do ponto de vista teórico, mas evidentemente pela atualização que ela operou na luta de classes, e também pelos limites, contingências, taras e cicatrizes que ainda em seu tempo continuavam a ser sofridas, dada a incapacidade de superação dos seus efeitos de repetição.

A questão é saber de que modo deveríamos retornar a tais momentos da história, até que ponto é necessário analisar as contingências que a marcaram e qual o peso que esse acontecimento deve ter, na militância. Para isso, seria preciso aprofundar a análise das circunstâncias e do contexto no qual foi produzida a ruptura leninista, a fim de determinar quais obstáculos tornaram possível que ela assistisse, impotente, à escalada do stalinismo. ${ }^{2}$

2 Essa análise está longe de ser datada e irrelevante, para os dias atuais. Em Revolução Molecular, livro que analisa o advento do neoliberalismo europeu, Guattari vai utilizar o modelo de gestão policial soviético como base para a construção de democracias totalitárias na Europa. 
Guattari destaca que os bolcheviques se mostraram, desde o início, incapazes de assumir a conduta das massas. $\mathrm{O}$ aparelho do partido, ainda modesto e clandestino, foi obrigado a montar um Estado, um exército, e ainda se via na obrigação de coordenar as lutas revolucionárias pelo mundo. "O aparelho estava em todos os lugares e se sentia responsável por tudo." (GUATTARI, 1974, p. 186).

O partido leninista não estava pronto, sobretudo no plano teórico, para permitir uma verdadeira criatividade institucional. Nada saiu do estilo tradicional, seja sindicato, seja organizaçáo feminista, seja ainda de jovens. Nenhuma inovação institucional ocorreu. Pelo contrário, para manter a coesão interna e por razões propagandistas, o partido deixou que proliferasse uma fantasmagoria coletiva de onipotência com proporçóes megalomaníacas. O partido tinha sido investido de uma vocação messiânica, designado pela história para julgar o que era bom e o que não era, distinguir o verdadeiro e o falso. O resultado foi a perseguição e a eliminação de todas as oposiçôes.

$\mathrm{O}$ que ocorreu neste momento se repetiu em outros lugares ad infinitum. Enunciados cristalizados e separados definitivamente de suas situaçóes de enunciação. Postos em posição de enunciados dominantes, sua função foi em seguida controlar toda enunciação em situação de ruptura. Atitudes, de um estilo "bolcho" profissional, um gosto perverso pela ruptura inicial, associada a uma grande maleabilidade tática flertando às vezes com a duplicidade, foram lançadas no mercado da subjetividade militante. Muitos especialistas em fonética, semântica e fonologia poderiam analisar este acontecimento e demonstrar a origem de toda uma cristalizaçáo de traços linguísticos, de maneiras, sempre as mesmas, de martelar fórmulas estereotipadas, qualquer que seja a linguagem de empréstimo e que continua sendo a realidade única de muitos militantes hoje em dia. (GUATTARI, 1974, p. 189).

Eis a máquina leninista: a questão em torno da qual gira sua época é, segundo Guattari, a de saber por que outra máquina ela poderia ser substituída, uma que fosse mais eficaz e menos perniciosa em relação ao desejo das massas.

Assim, é sob o signo da ruptura que Guattari busca pensar o que é da natureza da política, e não é por acaso que seu pensamento se construirá a partir de uma ruptura que se dá ao mesmo tempo em dois campos: o do marxismo e o da psicanálise. Trata-se de uma ruptura com o estruturalismo de Lacan e de Althusser. A função do conceito de máquina visa, portanto, à produção de uma análise histórica que não a entende como desenvolvimento, porém, como um 
corte, Logo, nesse contexto, a questão central para Guattari será pensar a história com base em um conceito renovado de sujeito histórico e político - eis a razão pela qual ele precisa atacar, ao mesmo tempo, Lacan e Althusser.

\section{A MÁQUina CONTRa A ESTRUTURA}

Guattari (1974) sublinha que o objetivo da distinção entre máquina e estrutura objetiva clarificar as posiçóes particulares da subjetividade em relação à história e ao acontecimento. Vemos que uma nova questão aparece no horizonte da relação entre psicanálise e política.

A estrutura é definida aqui, a partir de Deleuze, como generalização caracterizada pela posição de troca ou de substituição de particulares, enquanto a máquina diz respeito a uma singularidade intercambiável e incomunicável (GUATTARI, 1974) Essa distinção prenuncia a crítica que será apresentada em Anti-Édipo, a respeito do caráter representativo da estrutura. Quando observamos a teoria lacaniana dos quatro discursos, fica evidente que um sujeito só pode emergir, se for capaz de romper o ciclo instaurado pela mediação do saber entre dominador e dominado. O mesmo vale para a relação demanda/ desejo. O desejo surge, quando um sujeito rompe com a demanda do Outro ou se recusa a limitar seu desejo à demanda socialmente reconhecível e aceita.

O sujeito da estrutura, segundo Guattari (1974, p. 241), deve ser reportado a uma "metade", o eu, oposto ao sujeito do inconsciente. O sujeito do inconsciente, para ele, está do lado da máquina, literalmente ao lado. Ele é um ponto de ruptura da máquina. A máquina descreve, portanto, uma transformação histórica e social, um acontecimento cujo ponto de ruptura seria o surgimento de um sujeito inconsciente, de um desejo, de um novo desejo. Ou seja, a estrutura lacaniana descreve o funcionamento do "eu", sofrimento imaginário, patologias particulares e sociais, mas não singularidades.

É, por conseguinte, apenas fora da estrutura que um sujeito pode verdadeiramente emergir. Daí a necessidade de demonstrar que a revolução pode ser um ciclo que retorna ao ponto de partida, isto é, um processo no interior do qual o "revolucionário" é aquele que histericamente apenas afirma sua posição de saber, sua consciência sobre a necessidade de sua existência para a manutenção de um sistema de exploração e dominação. A histeria é apenas tomada de consciência, é preciso romper com a cadeia (ordem social) que sustenta a demanda. Se Lacan descreve a natureza dessa estrutura de 
dominação, Guattari está preocupado não com as estruturas que saem às ruas para afirmar seu saber e exigir reconhecimento ou reparação, todavia, com o sujeito dos acontecimentos, aqueles capazes de romper com as máquinas e com as estruturas de produção capitalista, um sujeito político, da história.

A estrutura posiciona seus elementos a partir da relação que estabelecem uns com os outros, de tal maneira que a estrutura pode ser associada, como elemento, a outra estrutura. Isso coloca um problema para o materialismo histórico e dialético. Como compreender a história e sua natureza, quando um modo de produção é tomado como uma estrutura? Ela se reproduz devido à sua relação com outras estruturas? É assim que podemos pensar o materialismo dialético, como história de suas estruturas, de suas relaçôes e de seus modos de produção e reprodução? Para Guattari, uma compreensão dessa natureza, meramente formal, será sempre abstrata. Essa parece ser a posição do estruturalismo de Lacan ou Althusser.

Uma posição formalista que parte das formas transcendentes, universais, cortadas da história e que se incarnam em substâncias semiológicas, [por isso, era preciso] partir das formaçóes sociais e dos agenciamentos materiais para extrair (abstrair) os componentes semióticos e as máquinas abstratas tais quais a história humana e cósmica as propóem. (GUATTARI, 1979, p. 12).

No interior do estruturalismo, o sujeito também é compreendido como sistema de definição recíproca, uma estrutura em relação com outras estruturas políticas, sociais, culturais, econômicas. A estrutura é, portanto, um processo de "totalização destotalizada", porque cada elemento se define em relação aos outros, de sorte que todos os elementos fazem parte da estrutura, mas parcialmente, ou seja, não cessam de enviar-se e reenviar-se uns aos outros, produzindo novas relaçóes e novos sentidos. Assim, o sujeito que escapa de uma estrutura é recolocado ou já estava em relação com outra estrutura.

Já a máquina não é compreendida como um discurso ou um processo de representação ou mesmo resultado de uma determinação transcendente; ela não descreve a maneira através da qual um modo de produção determina relaçóes sociais, no interior de estruturas diversas. Ela também não descreve um processo de alienação, na verdade, enquanto corte ou ponto de ruptura, a máquina está mais próxima do que Guattari entende por sujeito do inconsciente. Um sujeito que não se define em relação ao saber ou ao gozo, contudo, em relação à história e aos acontecimentos. 
A máquina é descentrada, excêntrica ao sujeito, esse está sempre em outro lugar. A máquina é um acontecimento, ela "marca uma data, um corte não homogêneo à uma representação estrutural." Ela descreve o momento em que a estrutura expõe suas fissuras, os lugares não são mais os mesmos, a ordem social se transforma. "Cada máquina é negação, morte por incorporação (ou dejetos) da máquina que ela substitui. Potencialmente, ela entretém os mesmos tipos de relação com a máquina que a sucederá." Guattari alude aqui a um processo de transformação histórica, movido por um inconsciente, um sujeito que não pode ser representado. Isso não significa, à maneira de Reich, uma distinção entre irracionalidade e racionalidade. Num primeiro momento, trata-se de afirmar que a relação entre modos de produção no interior da história e entre diversas esferas da vida social (economia, cultura etc.) não pode ser compreendida como relação de determinação estrutural. $\mathrm{O}$ que isso significa?

Partindo da afirmação de Marx, segundo a qual o modo de produção tem por objetivo a reprodução do trabalhador nas e com as condiçóes objetivas de sua existência - ou seja, um modo de produção não produz apenas coisas, ele é um modo de produção social, modo de produção de relaçôes sociais - Balibar, em Ler o Capital, conclui que a produção de relaçóes sociais é produção de coisas e indivíduos, através das relações sociais, uma produção no interior da qual os indivíduos são determinados a produzir coisas e a ser produzidos por uma forma específica de relação social. Quer dizer que a produção de relações sociais "[...] é uma determinação de funçôes do processo social de produção, processo sem sujeito." (BALIBAR, 1965, p. 517).

Se o modo de produção é compreendido como uma estrutura transcendente que determina a totalidade das relaçóes sociais, isto é, que produz coisas e indivíduos, como compreender o surgimento de um modo de produção no interior da história? Como compreender a transformação de modos de produção e, por consequência, como compreender a transformação das relaçóes sociais no interior da história? Sobretudo, como é possível compreender essas transformaçóes, se estamos diante de estruturas que funcionam sem sujeito? E a questão guattariana não é apenas de produzir um diagnóstico de seu tempo, uma análise de conjuntura capaz de demonstrar que o modo de produção do capitalismo atual é responsável pela totalidade das relaçôes sociais: é, com efeito, de saber como transformar a vida social e seu modo de organização: "Se olharmos para o Oeste, o Este, ou o Sul, a questão é a mesma: como organizar de outra maneira a sociedade." (GUATTARI, 1979, 
p. 217). Para isso, era preciso pensar o funcionamento da história e a natureza dos acontecimentos, era preciso romper com o marxismo-estruturalista, era preciso pensar não apenas estruturas e sua manutenção, mas cortes, rupturas - elas é que produzem a história como acontecimento.

A questão, portanto, de acordo com Guattari, não será de compreender a história como processo de produção de relaçóes sociais, ou como organizada pela sucessão de estruturas ou modos de produção, nem como resultado do desejo de sujeitos conscientes, autônomos e livres. Para ele, "são as máquinas, todas as máquinas que funcionam como a história real, pelo menos, enquanto elas continuam constantemente abertas aos traços singulares e às iniciativas criativas." (GUATTARI, 1979, p. 217). Ou seja, trata-se de apontar aqui a ausência de um lugar no interior da determinação estrutural para aquilo que torna possível um acontecimento. $\mathrm{Na}$ medida em que o modo de produção é tomado como determinação das relações sociais e subjetivas, determinação transcendente, o marxismo estruturalista se fecha para a análise da história real, concreta, aberta às intervençóes subjetivas e produzida pela ação humana.

Assim, o conceito de máquina visa, ao mesmo tempo, a descrever o inconsciente e os processos sociais e materiais no interior da história. "O sujeito e a máquina são indissociáveis. Há uma parte de subjetividade em todo agenciamento material. E reciprocamente, há uma parte de sujeição maquínica em todo agenciamento subjetivo." (GUATTARI, 1979, p. 179). A função do conceito de máquina é justamente abrir espaço para um pensamento da ruptura. A história não seria um processo de produção de relações sociais sem sujeito, mas um processo maquínico, produtor de relaçóes materiais e sociais, de indivíduos sujeitados e de sujeitos, os quais sustentam ou transformam os modos de produção ou a história, porque se conectam a eles de maneira absolutamente inconsciente, como máquinas, constantemente permeáveis a iniciativas singulares. A questáo seria, por conseguinte, a de pensar em que condiçôes uma ruptura é possível, uma ruptura que fosse capaz de dissociar ou de distinguir sujeito e máquina, de distinguir a singularidade subjetividade e a sujeição maquínica.

Para construir esse novo sujeito, seria preciso, evidentemente, partir da noção de trabalho. Afinal, é a contínua reprodução e eternização do trabalhador que constitui a condição sine qua non do modo de produção capitalista. O trabalho contemporâneo não estaria alienado por um deslocamento na posição do saber. Não se trata aqui de pensar a relação mestre-escravo, professor-estudante, analista-analisando como uma relação de dependência 
via confisco e monopólio do saber. O que significa que o trabalho intelectual e revolucionário não se dá sob a via da conscientização de classe que pode cair na posição histérica e na disputa abstrata por reconhecimento via recognição, isto é, em um ciclo onde o explorado afirma e reconhece sua posição e espera do mestre o reconhecimento de sua importância, no interior do processo produtivo via compensação financeira, sobretudo, estilo negociação sindical ou criação de políticas públicas. Se há alienação, ela deve ser pensada como um processo que se dá entre o trabalhador e a máquina.

Com a revolução industrial, a evolução contínua e espasmódica do maquinismo, com transformaçóes sucessivas (do trem ao computador), corta e recorta as antigas ordens de métiers. Cada profissáo, cada trabalho passa a ser determinado pelas máquinas. $\mathrm{O}$ trabalhador perde a legitimidade que o pertencimento a um "corpo de trabalhadores" lhe conferia (GUATTARI, 1974, p. 242).

As instituiçóes surgem e se desenvolvem para preencher o vazio deixado por tal transformação. Seu caráter ideológico não reside apenas em seus aspectos fascistas e paternalistas, com suas divisas sobre o trabalho, a família e a pátria, mas também na própria esquerda socialista (incluindo o modelo cubano) com sua apologia opressora do trabalhador e o culto da máquina, elevada à categoria de herói moderno.

A máquina passou ao coração do desejo. Guattari menciona, à maneira de Marx, em seus manuscritos, um "apagamento do indivíduo em relação à sua própria produção.” (GUATTARI, 1974, p. 243). O trabalho humano não passa de um "sub-conjunto residual do trabalho da máquina." (GUATTARI, 1974, p. 242). Nesse ponto, o sujeito inconsciente, maquínico, ou dejeto da máquina, aparece como extrapolação da teoria lacaniana do significante: "significante destacado da cadeia estrutural inconsciente que funciona como representante da representação da máquina.” (GUATTARI, 1974, p. 243). A questão é saber como esse processo de desprendimento da própria estrutura pode levar à produção de um sujeito revolucionário e como fazer para que ele escape de outras estruturas que pretendem representá-lo. A resposta para essa questão não é nada simples, afinal, é a um sujeito inconsciente que se alude aqui.

Por essa razão, essa subjetividade não é representável. Ela é essencialmente heterogênea em relação à ordem estruturalmente estabelecida. Nem por isso ela deixa de ser a "raiz fundadora das diferentes ordens estruturais." (GUATTARI, 
1974, p. 243). A novidade é que não há, no interior desse processo, uma causalidade como a que anima as estruturas lacanianas, onde a perda requer o impossível e a falta tem no mito o seu outro. Não se trata de pensar a máquina do ponto de vista simbólico-imaginário, por isso, ela não poderia mais ser um produto derivado da ordem representativa, quer dizer, da linguagem. Para pensar o sujeito além ou aquém da representação, Guattari (1974, p. 243). introduz a noção deleuziana de diferença:

A essência da máquina é precisamente essa operação de desprendimento de um significante como representante, como "diferenciador", como corte causal, heterogêneo à ordem das coisas estruturalmente estabelecida. Essa operação liga à máquina ao duplo registro do sujeito desejante e de seu estatuto de raiz fundadora das diferentes ordens estruturais que a ele correspondem. A máquina, como repetição do singular, constitui um modo, e mesmo o único modo possível, de representação unívoca das diferentes formas de subjetividade na ordem do geral sob o plano individual ou coletivo.

Se um modo de produção, produtor de relações sociais, pode ser considerado sem sujeito, o que o conceito ou problema que a reprodução dos meios de produção coloca é não apenas, segundo Balibar, o da consistência da estrutura, mas também o da determinação necessária do movimento de produção pela permanência dessa estrutura. $\mathrm{O}$ conceito de reprodução social "é o conceito da permanência dos elementos iniciais no funcionamento mesmo do sistema, portanto, o conceito das condições necessárias da produção, e que justamente não são criadas por ela." (BALIBAR, 1965, p. 519) Há, portanto, um ponto cego no interior do determinismo dos meios de produção que aparece, quando a questão não é somente pensar um modo de produção como determinação transcendental da ordem social, mas o modo de reprodução das relaçóes sociais. O que faz com que a ordem social se mantenha, se reproduza? O conceito de máquina visa a preencher essa lacuna. Ela é que determina as condiçôes da produção, ela é que determina a natureza do trabalho e o lugar do trabalhador, nas relaçóes sociais.

Há, portanto, uma máquina entre o modo de produção e sua reprodução. Afinal, a máquina é um corte histórico, heterogêneo, e que, por ser diferenciante, é capaz de representar um desejo e estruturar diferentes ordens sociais. Além disso, se a máquina rompe uma determinada ordem causal, no interior da história, se ela provoca um corte histórico, ela é também o lugar de onde pode emergir um sujeito. Isso só pode ser possível, porque 
a máquina possui um elemento diferenciante. Ela é o nome de um meio de produçáo que, ao mesmo tempo, transforma a história e produz sujeitos, os quais, como a máquina, possuem um elemento que torna possível a ruptura em relação à própria ordem por ela estabelecida.

Guattari não acreditava que a visão geral, exclusiva da estrutura, fosse capaz de explicar o processo de produção de sujeitos, no interior do capitalismo. Essa visão estruturante cria a ilusão de um ponto de apoio possível em um estado estrutural pré-existente. Não é possível pensar uma cadeia significante pura, metalinguagem, referente absoluto, pois essa visão mascara o caráter contingente e singular dos acontecimentos, a natureza do corte operado pelas máquinas na história e em seu funcionamento, inclusive, na maneira através da qual novos sujeitos serão produzidos. O sujeito ficaria reduzido ao plano da representação, informação e comunicação dos códigos sociais e de outros modos de estruturação. Ele é reduzido à condição de objeto, produto, mas não agente. Segundo Guattari (1974, p. 243), era preciso pensar o lugar do sujeito da história entre estrutura e máquina, a partir de um corpo atravessado e dilacerado por cadeias significantes.

Guattari (1974, p. 175) define Althusser e seus pares como os "[...] padres da pura teoria, os últimos guardiōes da cientificidade dos conceitos." Guattari critica o caráter transcendental da estrutura e suas consequências na relação entre determinação significante e história.

Para Lacan, diz (Guatari, 1974, p. 174),

[...] o significante não tem história, ele não é no tempo, ele pertence à ordem da estrutura [...] é um material a-histórico de non-sens constitutivo das significaçóes históricas: puro efeito de corte ou ressonância, acidente contingente que só se proclama posteriormente como tendo sido o primeiro termo de uma série.

A estrutura cristalina se situa fora da história, mas lhe fornece seu fundamento, operação Althusser, segundo Guattari. A subjetividade é totalmente dependente de uma determinação causal estrita, a estrutura. Ela e o significante são reversíveis, o que significa que a práxis não tem nada a ver com essa subjetividade pura, formal. Ou seja, não há lugar para a práxis subjetiva, no interior dessa determinação causal transcendente que paira fora da história e do real. 


\begin{abstract}
Não há na natureza nem significante nem significado fora de uma relação ao sujeito; o sujeito é um corte significante produtor de enunciados, começando por aqueles que denunciam a presença do sujeito na enunciação. $\mathrm{O}$ círculo corre o risco de se fechar. É a tentação estruturalista. Considerando que o sujeito se remete ao outro - miragem da intersubjetividade -, enquanto que o significante se remete ao significante - miragem de uma linguística ainda em suas línguas - cindida de toda realidade, funda-se assim um sujeito sem consistência - simples operador simbólico - e um tempo significante que não é mais, de fato, nada além de um tempo lógico. O sujeito só está lá para pontuar a batida de uma partitura significante que nunca pode ser executada na realidade. $\mathrm{O}$ real e a história se tornam tributários de uma ordem simbólica eterna dos quais eles estão definitivamente cindidos e que os anula essencialmente. (GUATTARI, 1974, p. 175).
\end{abstract}

Mesmo a insistência de Lacan, em salientar que a relação entre sujeito e significante é profundamente dissimétrica, não consegue escapar da idealidade e da pureza da estrutura. O sujeito barrado é tributário de sua relação à residualidade, do objeto $a$ que assegura seu estatuto, por isso, ele é marcado por esse traço que o desclassifica como puro significante e o aliena da condição desejante através dos objetos parciais. Assim, completa Guattari (1974), ele recai na paixão mortífera de abolição em uma pura e ideal estrutura.

Existem duas maneiras de fazer uso do significante. A primeira é transformá-lo em uma categoria universal, como a extensão ou a duração: essa é a astúcia de um novo idealismo que desconsidera que o signo esteja diretamente relacionado ao sentido e à realidade social. A segunda maneira é a lacaniana: o significante é um filtro a partir do qual os efeitos do inconsciente podem ser repertoriados, o que não pode ser simetrizado; o que não é recuperável pode ser indexado sob a forma do sonho, do ato falho, do acting out, da transferência etc.

Guattari propóe uma outra forma de compreender o significante, o sujeito e a história. Ele entende a história como sujeito. Há um realismo residual na história, uma realidade inexpugnável da qual não é possível fazer economia. A desrealizaçáo da história encontra seu limite no fato contingente de que são os homens e ninguém mais que a fazem e a falam. Logo, o significante emerge enquanto tal apenas a partir do momento em que um sujeito irrompe e "[...] coloca tudo em questão e refunda a enunciação, um trabalho do significante como expressão do sentido, de um corte possível na 
ordem dada, como ruptura, revolução, apelo para uma reorientação radical." (GUATTARI, 1974, p. 176).

A ideia de corte significante agora se transforma na ruptura, na cisão operada na máquina: "[...] mascarada por trás da estrutura, esperando, o corte maquínico é o sujeito em conserva, o tempo em bateria. Enquanto a estrutura não se move, o sujeito não se produz." (GUATTARI, 1974, p. 181). Guattari é muito claro, ao afirmar que só é possível "[...] sair do impasse estruturalista considerando que um efeito do sentido só pode produzir consequências no plano do significado quando potencialidades subjetivas são liberadas, quando há uma ruptura no significante." (GUATTARI, 1974, p. 180). O conceito de máquina visa, por conseguinte, em função do estado atual do trabalho, a pensar o lugar de emergência de um sujeito, entre a estrutura que mantém em funcionamento um modo de produção e exploraçáo e a máquina que altera a história, produzindo espaços, no interior do quais sujeitos podem ao mesmo tempo romper com a estrutura e com as máquinas.

\section{As máquinas E O ESTAdo ATUAL da LUTA DE ClASSES}

Guattari não se limita às críticas teóricas, porém, procura colocar em evidência as questóes práticas e políticas postas por essa noção de estrutura. E, nesse caso, ele parte do fenômeno de grupo. Ou seja, trata-se de pensar modos de organização social que não são individuais, o que implica pensar toda forma de organização institucional ou com pretensão institucional, todo tipo de organização que não seja a da subjetividade-individual do divã psicanalítico. Como um grupo de pessoas pode se organizar, escapando de uma forma de organização centralizadora e hierarquizada? É possível criar instituiçôes não disciplinares? É possível subverter a lógica das instituiçóes, alterar seu modo de funcionamento?

Guattari concebe a estruturação de uma organização política como seu enrijecimento em torno de uma doutrina que a torna incapaz de produzir ideias e novas formas de vida. A estruturação reduz a experiência e a invenção a um saber com pretensóes de onipotência. A crítica ao lacanismo e ao marxismo althusseriano é também crítica ao Partido Comunista. Se a própria organização política não é capaz de escapar das formas autoritárias do Estado e de suas instituiçôes, como seria capaz de destruir ou sequer transformar essas instituições? 
O problema dos grupos sociais é que eles não possuem uma superfície de projeção (como os indivíduos e seus corpos); na verdade, grupos sociais "dispóem apenas de modos de decifrar e de se situar sucessivos e contraditórios, aproximativos e metafóricos, a partir de diferentes ordens estruturais, por exemplo, de trocas, de mitos, etc." (GUATTARI, 1974, p. 243). É por essa razão que o desejo pode ser "reprimido", ou melhor diríamos, regulado e gerenciado pela ordem social. A questão é, portanto, saber compreender, em primeiro lugar, que movimento é esse, responsável por conter a potencialidade das máquinas, produzindo sua estruturação. Essa é a função do conceito de antiprodução: explicar de que forma as singularidades produzidas por transformações históricas são contidas, desviadas ou minadas, de sorte que toda sua potencialidade criativa é limitada ou destruída.

O primeiro movimento da antiprodução consiste em impedir todo tipo de passagem de um sistema de produção para outro. Se a máquina se define como o corte subjetivo que caracteriza toda forma de produção, a antiprodução procura igualar e tornar equivalentes todas essas ordens, impedindo a passagem de um modo para outro, impedindo as rupturas. Quer dizer, a noção de estrutura teria um papel ideológico, porque, ao igualar todas as esferas da vida social em função de uma forma única, impede a manifestação da singularidade e da heterogeneidade. Ela não é capaz de tornar visível o que, por natureza, é singular. Coloca-se sob o mesmo plano o que ocorre na fábrica, na escola, no atelier, na produção literária, poética, onírica etc. A antiprodução é tudo aquilo que é posto sob a forma das "relações de produção" (GUATTARI, 1974, p. 244). O reequilíbrio imaginário que ela opera é o da fantasia transicional. Não se trata de um aparato conservador ou antirrevolucionário que objetiva conter o tempo e reverter a história; a antiprodução organiza mudanças e transformaçôes no seio de uma área social determinada, promove a generalizaçâo de um novo modo de produçáo, acumulação, circulação e distribuição. Ou seja, a antiprodução substitui a ruptura, que é capaz de produzir novas potencialidades, por uma fantasia de transição, por um processo de desenvolvimento, o qual nada mais é do que a propagação ou a extensão de um único modo de produção para todas as esferas da vida social.

A própria teoria lacaniana parece assombrada por esse tipo de fantasia transicional. É isso o que sua teoria do significante parece indicar. Tomemos o objeto $a$, causa do desejo: o tipo de relação estrutural que ele instaura perturba o equilíbrio estrutural do indivíduo, afinal, o desejo é um corte metonímico, 
uma relação parcial que se estabelece a partir de relaçóes de alteridade posicionadas de maneira específica, com base em cada etapa do processo. A crítica de Guattari consiste em afirmar que a representação de si mesmo e do processo histórico pelas grelhas da linguagem conduz apenas a um impasse, porque ela nos conduz a um ponto de ruptura onde não se ouve nada além do apelo de uma alteridade repetida (espécie de dialética negativa). Um eterno conflito entre o "eu" e o Outro, como instância imaginária que simboliza a totalidade da ordem social. A fantasia individual representa a impossibilidade de passagem entre diferentes planos, mantendo segura a individualidade sem portas nem janelas imersa em uma exterioridade totalizada. "O objeto do desejo descentra o indivíduo a beira dele mesmo, no limite do outro; ele encarna a impossibilidade de um refúgio absoluto de si mesmo em si mesmo e igualmente a impossibilidade de uma passagem radical ao outro." (GUATTARI, 1974, p. 244).

O problema que Guattari almeja enfrentar, tanto em sua prática analítica quanto em sua atuação militante, é a produção de enunciados coletivos, sociais. Enunciados que sejam a expressão de um desejo de transformação da vida social, de seus modos de organização. Assim, o problema que a psicanálise parece expor é um sintoma do problema que corrói a imaginação nas lutas políticas.

Se continuarmos com noçôes como Eu ideal e Ideal do Eu, consideraremos um sujeito que busca se integrar, não a um campo social dado, mas unicamente, pela sua funçáo de fala, ao campo do Outro. Partimos de uma situação inicial marcada por uma contingência absoluta, de um narcisismo absoluto (das Ding), para chegarmos a uma abertura hipotética sobre a sociedade, a uma "cura" que desemboca na indeterminação, e assim, tem como consequência toda espécie de problemas de integraçáo a grupos sujeitados (escola, grupo esportivo, caserna, sindicato, partido, etc.). $\mathrm{Na}$ verdade, partimos de uma constelaçáo social inconsciente singular para chegarmos em uma atualizaçáo do Inconsciente abstrato. (GUATTARI, 1974, p. 44).

Se a psicanálise tem um fundamento filosófico, ele implica que a psicanálise seja também a elucidação de impasses culturais e sociais no interior do qual ela mesma se insere. Logo, Guattari rejeita o ponto de vista do Eu, do indivíduo, e prefere a análise de instituiçóes e de grupos, para evitar essa falsa oposição, no fundo absolutamente abstrata, entre o Eu e o Outro ou o indivíduo e a "ordem social". Trata-se de escapar dessa generalização e de 
buscar análises em situação concreta. A oposição eu/Outro se exime de pensar o que está entre o Estado e o indivíduo, entre a lei e o cidadão, ou seja, as instituiçôes, responsáveis pelo estabelecimento das normas de comportamento que sustentam o modo de vida social, instituiçóes que promovem e produzem na prática formas de sujeição.

É analisando as fantasias de grupo que Guattari pensa a questão das lutas políticas. Ele busca, assim, num primeiro momento, detectar a natureza da antiprodução no interior dos grupos ou instituiçôes, com o objetivo de compreender que mecanismos entravam a produção de uma singularidade subjetiva. Assim, surgirá a distinção entre grupo sujeito e grupo sujeitado, a qual depende do tipo de fantasia que assombra os grupos sujeitados e que se deve justamente à oposição entre o particular e o geral.

A diferença entre a fantasia individual e a fantasia de grupo é que o grupo não possui uma superfície, como o corpo, que possa servir de ponto de referência para o funcionamento do desejo, pontos de ancoragem, de apelo à ordem das verdades singulares, como são as zonas erógenas (GUATTARI, 1974). Isto é, se a fantasia individual distingue o outro a partir do corpo próprio do indivíduo, o outro é o não-eu, a fantasia de grupo é muito mais heterogênea. Como o grupo não dispóe de um corpo que sirva de amparo à fantasia, ele tende a sobrepor, a substituir e trocar os planos distintos da vida social, de forma que permanece condenado a girar em torno se si mesmo. Os efeitos circulares da estrutura conduzem a zonas de impasse, de interdição, a vácuos intransponíveis e a toda uma zona sem sentido.

Guattari descreve, em seguida, problemas próprios da contestaçáo que só poderiam ser postos à luz por alguém que possui não apenas experiência psicanalítica e clínica, mas na militância política. Trata-se de procurar razóes que expliquem maio de 68, que sejam capazes de diagnosticar os problemas da organização e da crítica que bloquearam o prolongamento do acontecimento, no campo do grupo, no interior de grupos e organizaçóes, sejam elas políticas, literárias ou médicas (correspondem, na verdade, a todo tipo de organização coletiva institucional ou com pretensão institucional):

A fantasia envia a fantasia como uma moeda de troca, moeda sem padrão ou corporeidade, sem um ponto de consistência que lhe permita ser enviada nem que seja de maneira parcial a outra coisa que não seja uma topologia decalcada exclusivamente da ordem geral. (GUATTARI, 1974, p. 245). 
O grupo fantasia o acontecimento, através de um vai e vem ininterrupto entre o particular e o geral, o indivíduo e o Estado. Todo o problema se constitui justamente na incapacidade de estabelecer distinçôes entre produçôes distintas, espaços distintos da vida social. O menor é enviado ao Estado e à ordem, sem que as condiçôes concretas e positivas de produção da sujeição sejam determinadas. Não por outra razão, os equivalentes da subjetividade de grupo, suas fantasias, giram em torno de tal líder, daquele bode expiatório, daquela cisão ou ruptura, ou da ameaça imaginária vinda do outro grupo.

A identificação do igual e do diferente, no interior dos grupos, se opera segundo uma lógica imaginária de segundo grau. É a representação imaginária do outro grupo que funciona e determina a posição do primeiro.

A fantasia que aprisiona a imaginação institucional e as formas de organização entre o particular e o universal tem suas razôes históricas e sociais, entre as quais está a integração da classe operária. Antes mesmo de maio de 68, Guattari já insistia que esse era o maior problema político da França, que o PCF inclusive não cessava de nutrir. E, nesse sentido, suas teses estão muito próximos das teses benjaminianas sobre a história, que tomam a integração da classe operária como uma das razóes para o sucesso do fascismo.

Esse processo vem ocorrendo desde o início do século XX. O movimento operário foi se integrando à ordem legal, diante de protestos cada vez mais tímidos, ao mesmo tempo em que o "[...] espírito da luta de classe se arrefecia principalmente entre os militantes comunistas no contexto ideológico da existência pacífica entre os regimes, e implicitamente, entre as classes." (GUATTARI, 1974, p. 195) Se atentarmos para os fatos, podemos perceber, segundo o autor, que os movimentos reivindicativos permaneceram afastados de todo e qualquer movimento político que poderia colocar seriamente em questão o capitalismo.

O PCF começava a adquirir uma "cara" mais liberal, apregoando alianças, aceitando a ideia de um pluralismo partidário como sendo capaz de instaurar o socialismo. Estaríamos diante de um processo de degenerescência da vida política da classe operária e de degenerescência da vida política em geral. Quando se debate política, trata-se apenas de organizar uma pseudoparticipação, uma consulta dos usuários, para levá-los a se interessar a respeito de questóes sobre seu nível de vida, questôes que tocam a normalização de processos econômicos, ajustes no plano regional e nacional, investimentos e fluxo de mão de obra, de consumo etc., tudo manipulado por lobistas e 
tecnocratas (GUATTARI, 1974). A burguesia favorece essa despolitização, já que os centros de decisão econômica não são localizáveis nos quadros nacionais existentes e se deslocaram para outras entidades imperialistas e oligopolistas, as quais nem sequer coincidem com os grandes mercados, como a comunidade econômica europeia.

A luta operária tende a se neutralizar, no interior dessas novas organizaçóes. Quando se fala em governo de esquerda, ninguém hesitaria em convocar o PCF, afinal, seus membros são mais eficazes que a polícia, para conter todo e qualquer movimento de massa. Nesse quadro, o PCF parece absolutamente incapaz de combater os mitos da sociedade de consumo, e todos aqueles que, como Guattari, fizeram a travessia, a passagem do PCF para os pequenos grupos, grupelhos, são perfeitamente conscientes de que ao menos uma lição pode ser tirada dessa situação: “[...] nenhum lugar de militância escapa de uma carência teórica e prática totais, caraterizada pelo fato de que a problemática que os agita está vencida há pelo menos quarenta anos!" (GUATTARI, 1974, p.197.)

A realidade da classe operária, da juventude, dos estudantes é permanentemente definida pela produção, pelas mercadorias, pelos resultados, índices e diplomas. Seu único recurso são essas associaçóes esclerosadas que pretendem representá-los, mas que na verdade, os substituem. Assim, tudo se conserva e se mantém graças à inércia desses objetos institucionais vazios de toda e qualquer substância, pura repetição de uma rotina burocrática e de uma rede de palavras vazias (GUATTARI, 1974).

O aparelho patronal, os sindicatos, o aparelho de Estado e suas instituiçóes são instrumentos de alienação da classe operária, ao mesmo tempo em que não poderiam ser abolidos em um passe de mágica. Eles são parte integrante da antiprodução. Toda tentativa para escapar dessa rede institucional só funciona como argumento para fortalecê-la: "vejam, nada é possível fora da Igreja, por pior que seja...” Organizaçôes socialdemocratas são vividas como um mal necessário, por isso, é preciso ter em mente que, conforme Guattari (1974, p. 199), “[...] a transformação dos grupelhos de esquerda depende do desdobramento de referências conceituais novas, da produção de novas formas de organização", porque o que está disponível no mercado do atual marxismoleninismo não seria capaz de nos dar nem sequer uma ideia.

A questão é saber de que maneira destruir esses "[...] miasmas participativos que intoxicam a vida operária”, impedir que ela se limite ao trade 
unionismo, isto é, impedir o primado da demanda sobre o desejo (GUATTARI, 1974, p. 200). O que gostaria de salientar aqui é justamente esse aspecto da análise de Guattari, a maneira como ele associa sindicalismo e demanda neurótica, socialdemocracia e um desejo que nem sequer pode se tornar visível, audível ou presente, pois é mascarado, refreado, anulado pelos cálculos, negociaçôes, reformismos e representações. Por conseguinte, a questão da análise institucional consiste nessa afirmação segundo a qual a política começa com uma ruptura, uma ruptura em relação a essa demanda que náo passa de expressão da alienação, desejo de reconhecimento do oprimido diante de seu próprio opressor. "O conceito de política não é o prolongamento simples da demanda.” (GUATTARI, 1974, p. 203). A questão política não passa, para Guattari, por definir a natureza da resistência individual, subjetiva contra o poder que nos oprime, todavia, por criar espaço no interior da vida social para a emergência de um desejo, novo. Trata-se de pensar e criar as condiçôes para que uma nova forma de organizar a vida social se torne o objeto de desejo e objetivo da luta política, a fim de que um enunciado coletivo emerja, o qual expressaria o desejo de uma outra vida, de uma outra forma de organizar a vida social.

Essa operaçáo começa com a análise da demanda, que é como um ácido que desencapa o acontecimento para aguçar sua capacidade de ruptura, de tal maneira que ele possa abrir a subjetividade social ao desejo, ou seja, evidenciar o caráter limitado e imaginário da demanda deve servir como combustível para que um desejo possa emergir, quer dizer, não se trata de limitar a política ao realismo das possibilidades dadas de antemáo, mas de criticar o caráter limitado e restrito do realismo incapaz de criar novos possíveis, de criar desejos. Assim, é apenas como ruptura que um sujeito pode emergir, é apenas como ruptura que um ato político pode ser dito como tal - ruptura que é sempre o produto de um desejo.

Conforme Guattari, só uma análise que se constitui sob o pano de fundo da práxis revolucionária poderia pretender uma verdadeira exploração do inconsciente, porque "[...] o inconsciente não é nada mais que o real por vir.” (GUATTARI, 1974, p. 204). Se Guattari dirige sua crítica à demanda política que surge no interior das sociais-democracias europeias. com a integração das organizaçóes da classe operária no interior do sistema capitalista, ou seja, a partir do momento em que os sindicatos se oficializam e se tornam órgão principal de negociação entre representantes de funcionários e patrôes, é porque esse talvez seja o momento em que as instituiçóes, de toda a natureza se 
cristalizaram definitivamente no interior das democracias europeias. Estamos aqui diante de uma crítica das instituiçóes cujo objetivo é liberar a classe trabalhadora da alienação promovida por sistemas de representação baseados em demandas limitadas. O problema da demanda é que ela não promove uma ruptura necessária para a existência mesma do político, ela mantém as instituiçóes em vigor, ela as sustenta. Um desejo rompe com a demanda e questiona o poder, ele coloca em questão a legitimidade do poder.

\section{Consideraçótes Finais}

Se um modo de produção é produtor de relaçôes sociais, o conceito de reprodução nos coloca diante da questão que o materialismo histórico deveria ser capaz de responder: como são criadas as condiçôes necessárias da produção? $\mathrm{O}$ althusserianismo entende que um modo de produção é um processo que cria relaçôes sociais sem sujeito; nesse sentido, as condiçóes necessárias da produção também seriam um processo que ocorre sem precisar de um sujeito? Se a resposta for positiva, o materialismo tem de enfrentar um grande problema: como conceber que haja história, que possa existir transformação no interior da vida social? Transformação que o próprio Marx concebe como açáo revolucionária, produzida por um novo sujeito, o proletariado.

Para Guattari, o formalismo althusseriano que toma o modo de produção como estrutura que determina, por sua vez, modos de relação entre sujeito e objetos e entre sujeitos faz economia da história real, contingente, concreta e material.

A grande diferença entre a noção de estrutura e a noção de máquina é que esta possui um elemento diferenciador. É porque concerne a singularidades que ela diz respeito à história. Se a estrutura como generalização que permite trocas e substituição de posições pode descrever a natureza de um modo de produção fixo, ela não é capaz de explicar a natureza das transformaçóes históricas. Por isso, Guattari insiste que a máquina se refere a uma singularidade intercambiável e incomunicável. No entanto, por mais que a máquina seja um processo diferenciante, ainda é preciso uma ruptura para que um sujeito possa emergir. Afinal, a máquina é também uma técnica de produção, a qual, no interior do capitalismo, priva o trabalhador de um pertencimento a uma ordem, a uma classe de trabalhadores. Daí a importância do conceito de antiprodução. 
Assim, o conceito de máquina visa ao mesmo tempo a compreender de que maneira um modo de produção é capaz de produzir sujeitos da história e modos de sujeição e alienação. Ele objetiva romper com o determinismo estrutural, seja lacaniano, seja althusseriano. A máquina é um processo de "focalização do desejo" que define acontecimentos históricos; ela pode ser, como vimos, tanto uma técnica de produção quanto uma descoberta, uma arma ou uma axiomática religiosa. Mas, em se tratando de máquinas, só podemos considerar as identidades e as trajetórias como relativas. $\mathrm{O}$ tempo maquínico não é o tempo da história-desenvolvimento, objetiva e linear: as causalidades não funcionam em um sentido único e, por essa razão, nunca podemos sustentar que tudo está decidido e determinado de antemão.

Afirmar que o inconsciente funciona através de um maquinismo significa afirmar o caráter concreto dessa produção que não pode ser compreendida a partir de essências não históricas (como a estrutura) e de análises orientadas por grandes conjuntos molares (a lei, o Estado, a cultura). A subjetividade humana já não possui um estatuto existencial excepcional. Sujeito e máquinas são indissociáveis; todo agenciamento material, todo fato social é subjetivo, mas também possui uma parcela de sujeição maquínica. O objetivo da esquizoanálise não é outro a não ser produzir conceitos capazes de nos guiar na análise dos diferentes tipos de agenciamento e de suas produçóes, separar a criação da repetição mortífera, o singular do mesmo, desembaraçar o fio e as ambiguidades que fazem com que o inconsciente oscile entre descargas reacionárias e potencialidades revolucionárias.

Guattari (1979, p. 216-217) se coloca a seguinte pergunta: "A esquizoanálise seria um novo culto da máquina?” A resposta seria talvez. Em todo caso, não se trata de um culto da máquina no interior do quadro posto pelas relaçôes sociais capitalistas. Náo se trata exatamente do velho sonho marxista o qual aposta que o progresso técnico que ameaça destruir a terra pode também ser a via de liberação humana. Afinal, não se trata de compreender que a história é guiada pelas máquinas produtivas e econômicas, mas de compreender que a máquina está sempre, como a história real, aberta aos traços singulares e às iniciativas criativas. Essa seria a única maneira de transformar o materialismo histórico em teoria do acontecimento e de compreender que o maquinismo inconsciente pode ser criativo. 
AGOSTINHO, L. D. Guattari: machines and political subjects. Trans/formlação, Marília, v. 43, n. 1, p. 103-126, Jan./Mar., 2020.

\begin{abstract}
From a presentation of the political and social context within which Guattari's work fits in, we seek to define the French political debate of the 1960s in the field of Marxism - especially historical materialism - on the question of the subject of history. The purpose of this article is to explain the reasons that lead Guattari to break with structuralism, represented in psychoanalysis by Lacan and Marxism by Althusser. The relevance of this article lies in the presentation of the concept of machine, which is defined in opposition to the concept of structure and that, joining history and unconscious, aims to trace the emergence space of a subject of history, of a political subject.
\end{abstract}

KeYwords: Historical materialism. Structuralism. Psychoanalysis and politics. History.

\title{
REFERÊNCIAS
}

BALIBAR, E. Lire le Capital. Paris: Éditions François Maspero, 1965.

GUATTARI, F. Psychanalyse et transversalité. Paris: Maspero, 1974.

GUATTARI, F. L'inconscient machinique. Paris: Éditions Recherche, 1979.

SIBERTIN-BLANC, G. D'une conjoncture l'autre. Deleuze et Guattari après-coup. Actuel Marx: Deleuze et Guattari, França, n. 53, pp. 28-47, 2012.

Recebido: 18/09/2017

Aceito: 30/06/2019 